\title{
Near Complete Rescue of Experimental Parkinson's Disease with Intravenous, Non-viral GDNF Gene Therapy
}

\author{
Yun Zhang ${ }^{1}$ and William M. Pardridge ${ }^{1,2}$
}

Received November 5 2008; accepted December 15 2008; published online December 23, 2008

\begin{abstract}
Purpose. Rats with experimental Parkinson's disease (PD) are treated with intravenous glial-derived neurotrophic factor (GDNF) plasmid DNA and non-viral gene therapy using Trojan horse liposomes (THLs) targeted with a monoclonal antibody (MAb) to the rat transferrin receptor (TfR). The GDNF transgene expression is under the influence of the rat tyrosine hydroxylase (TH) promoter.

Methods. The GDNF expression plasmid is designated pTHproGDNF. Rats were treated with 3 weekly injections of THLs starting 1 week after the intra-cerebral injection of 6-hydroxydopamine. The dose of the pTHproGDNF was $10 \mu \mathrm{g} / \mathrm{rat} /$ weekly injection. Rats were tested with three assays of neurobehavior, and terminal striatal TH enzyme activity was measured at 6 weeks following toxin administration, which is 3 weeks following the last administration of THLs.

Results. Apomorphine-induced contralateral rotation was reduced $87 \%$ by THL gene therapy; amphetamine-induced ipsilateral rotation was reduced $90 \%$ by THL gene therapy; whisker-induced forelimb placement abnormalities were reduced $77 \%$ with THL gene therapy. The improvement in neurobehavior correlated with a lasting $77 \%$ increase in striatal $\mathrm{TH}$ enzyme activity, relative to saline treated rats.

Conclusions. Near complete abrogation of the neurotoxin effects are achieved with multiple intravenous dosing of GDNF plasmid DNA gene therapy, using receptor-targeted THLs, and a region-specific promoter.
\end{abstract}

KEY WORDS: blood-brain barrier; brain gene therapy; non-viral gene transfer; tyrosine hydroxylase.

\section{INTRODUCTION}

Glial-derived neurotrophic factor (GDNF) is a potent neurotrophic factor for the catecholaminergic system (1-3), and GDNF protein therapy is a potential treatment of Parkinson's disease (PD). However, GDNF does not cross the blood-brain barrier (BBB) $(4,5)$. The intra-cerebral injection of either adeno-associated virus (AAV) or retroviral vectors expressing GDNF rescues neurons of the nigrastriatal tract in experimental PD (6-10). Since viral vectors do not cross the BBB, viral GDNF gene therapy of PD requires a trans-cranial injection of the virus. Since PD affects a very large number of individuals, it is desirable to develop non-invasive, non-viral GDNF gene delivery systems, which are administered by intravenous injection.

In a previous study, a modest rescue of the nigra-striatal tract in experimental PD was obtained with a single intravenous administration of a GDNF expression plasmid without viral vectors (11). The GDNF transgene was placed under the influence of the $8 \mathrm{~kb}$ rat tyrosine hydroxylase $(\mathrm{TH})$ promoter, so as to restrict GDNF expression to catecholaminergic cells in brain, thereby reducing off-target effects of

\footnotetext{
${ }^{1}$ Department of Medicine, UCLA, Warren Hall 13-164, 900 Veteran Ave., Los Angeles, California 90024, USA.

${ }^{2}$ To whom correspondence should be addressed. (e-mail: wpardridge@ mednet.ucla.edu)
}

the therapy. The GDNF expression plasmid DNA, designated pTHpro-GDNF, was delivered to brain with Trojan horse liposomes (THLs), also called pegylated immunoliposomes (12). The plasmid DNA is encapsulated in the interior of $100 \mathrm{~nm}$ liposomes, and the surface of the liposome is conjugated with several thousand strands of polyethyleneglycol (PEG). The tips of $1-2 \%$ of the PEG strands are conjugated with a receptor-specific monoclonal antibody (MAb), such as an MAb to the transferrin receptor (TfR). The TfR is expressed on both the BBB and on the neural cell membrane. The MAb portion of the THL binds the BBB receptor, and this triggers receptor-mediated transport across the $\mathrm{BBB}$, followed by receptor-mediated endocytosis into neurons behind the BBB (13-16). The purpose of the present study was to examine if a greater therapeutic effect could be obtained with a longer course of THL gene therapy.

\section{MATERIALS AND METHODS}

Materials. Palmitoyl-2-oleoyl-sn-glycerol-3-phosphocholine (POPC), dimethyldioctadecyl ammonium bromide (DDAB), distearoyl phosphatidylethanolamine (DSPE)$\mathrm{PEG}^{2000}$, and DSPE-PEG ${ }^{2000}$-maleimide were purchased from Avanti-Polar Lipids (Alabaster, AL), where $\mathrm{PEG}^{2000}$ is 2000 Da polyethylene glycol. The hand-held LipoFast-Basic extruders, 400-, 200- and 100-nm pore size polycarbonate 
membranes were purchased from Avestin Inc. (Ottawa, Canada). The genetic engineering, DNA sequencing, and restriction endonuclease digestion analysis of the pTHpro GDNF expression plasmid were reported previously (11). This plasmid encodes for the human prepro GDNF cDNA (GenBank P39905) corresponding to amino acids Met ${ }^{1}-\mathrm{Ile}^{211}$. The human prepro GDNF cDNA was subcloned into the pcDNA3.1 eukaryotic expression plasmid, and the GDNF cDNA is 3'-flanked by the bovine growth hormone (BGH) polyA (pA) sequence. The original cytomegalovirus (CMV) promoter was replaced by the $8 \mathrm{~kb}$ of the $5^{\prime}$-flanking sequence (FS) of the rat $\mathrm{TH}$ gene (11). The cloning of the rat $\mathrm{TH}$ promoter has been described previously (17). The GDNF cDNA is immediately preceded by the full Kozak sequence (GCCGCCACC).

Trojan Horse Liposomes. Plasmid DNA was prepared with the Endofree Plasmid Maxi Kit (Qiagen, Valencia, CA). Supercoiled DNA was ${ }^{32} \mathrm{P}$ labeled with $\left[\alpha-{ }^{32} \mathrm{P}\right] \mathrm{dCTP}$ by nick translation as described previously $(12,18)$. The pTHproGDNF plasmid DNA was encapsulated in THLs as described previously $(12,18)$. The liposome was $100-120 \mathrm{~nm}$ in diameter and the surface of the liposome was conjugated with several thousand strands of $\mathrm{PEG}^{2000}$. The tips of approximately $1-2 \%$ of the PEG strands were conjugated with the mouse OX26 MAb to the rat TfR. The OX26 MAb was purified by protein $G$ affinity chromatography from ascites. Any plasmid DNA not encapsulated in the interior of the liposome was quantitatively removed by nuclease treatment $(12,18)$. In a typical synthesis, $500 \mu \mathrm{g}$ of plasmid DNA was encapsulated within $20 \mu \mathrm{mol}$ of lipid. The THLs contained a range of 49-77 MAb molecules per liposome, and the efficiency of the conjugation of the MAb to the maleimide moiety of the PEG strands ranged from 75-95\%. The \% DNA encapsulation was $29 \pm 2 \%$ for the $13 \mathrm{~kb}$ pTHproGDNF DNA. The average diameters of the THLs was measured with a Nicomp model 380 Particle Analyzer (Nicomp, Santa Barbara, CA), and was $115 \pm 32 \mathrm{~nm}$ following conjugation of the MAb to the liposome.

Tyrosine Hydroxylase Enzyme Activity. TH enzyme activity in rat brain was measured with $\left[3,5-{ }^{3} \mathrm{H}\right]-\mathrm{L}-$ tyrosine as substrate; the labeled $\left[{ }^{3} \mathrm{H}\right]$-water and $\left[{ }^{3} \mathrm{H}\right]$-L-DOPA were assayed with a charcoal separation technique, and data reported as pmol per hour per mg protein, as described previously (19).

6-hydroxydopamine Model of Experimental Parkinson's Disease. All procedures were approved by the UCLA Animal Research Committee. Adult male Sprague-Dawley rats (supplied by Harlan Breeders, Indianapolis, IN) weighing 220-240 g were anesthetized with ketamine $(50 \mathrm{mg} / \mathrm{kg})$ and xylazine $(4 \mathrm{mg} / \mathrm{kg})$ intraperitoneally. Animals received a unilateral intra-cerebral injection of $8 \mu \mathrm{g}$ of 6-hydroxydopamine into the right medial forebrain bundle, as described previously (19). Rats were treated with either saline, or THLs containing $10 \mu \mathrm{g} /$ rat of pTHproGDNF plasmid DNA at 1,2 , and 3 weeks after toxin injection. Beginning 1 week after the toxin administration, rats were tested weekly for apomorphine- and amphetamine-induced rotation. For the apmorphine testing, rats were administered apomorphine $(0.5 \mathrm{mg} /$ $\mathrm{kg}$ ) injected intraperitoneally. Full $\left(360^{\circ}\right)$, contralateral rotations only were counted over $20 \mathrm{~min}$, starting 5 min after apomorphine administration. For the amphetamine testing, rats were administered amphetamine $(5.0 \mathrm{mg} / \mathrm{kg})$ injected intraperitoneally. Full $\left(360^{\circ}\right)$, ipsilateral rotations only were counted over $20 \mathrm{~min}$, starting $5 \mathrm{~min}$ after amphetamine administration. Rats were individually identified so that the rotations per minute (RPM) before and after gene therapy could be compared for each rat.

Vibrissae-Elicited Forelimb Placing Test. Each vibrissaeelicited forelimb placing trial was carried out as described by Anstrom et al. (20), and demonstrated by video (http:// homepage.psy.utexas.edu/HomePage/Group/SchallertLAB/ media.html). Each session included 120 trials (60 left side and 60 right side) in which a forelimb motor response to ipsilateral facial whisker stimulation was scored. In trials scored as a " 3 ", paw pads made full contact with table top. In trials scored as a "2", paw pads do not make contact with the table. In trials scored as a " 1 " the limb moves forward only. In trials scored as a " 0 ", the limb does not move. A maximal possible score is 180 , wherein the paw pad makes full contact with the table top in all 60 trials.

Statistical Analyses. Statistically significant differences were assessed with either paired Student's $t$-test or analysis of variance (ANOVA) using the Tukey post-hoc correction. A $p$ value $<0.05$ was considered significant.

\section{RESULTS}

The evolution of the 6-hydroxydopamine lesion was monitored by neurobehavior assays using apomorphineinduced and amphetamine-induced rotation, as described in Fig. 1. In the saline treated animals, the drug induced rotation increased linearly for 6 weeks following the single intracerebral injection of toxin, for both apmorphine (Fig. 1A) and amphetamine (Fig. 1B). The THL-treated animals were administered $10 \mu \mathrm{g}$ DNA/rat of the pTHproGDNF plasmid at 1, 2, and 3 weeks after toxin administration, as noted by the arrows in Fig. 1A. Following apmorphine administration, the contralateral rotation increased to $24.5 \pm 2.4 \mathrm{RPM}$ (mean $\pm \mathrm{SE}$, $n=10$ rats/group) by 6 weeks after toxin administration in the saline treated animals. However, in the THL treated animals, the apomorphine-induced rotation was not increased with time, and the animal rotation, $3.3 \pm 0.8 \mathrm{rpm}$, was decreased $87 \%$ (Fig. 1A). Following amphetamine administration, the ipsilateral rotation increased to $10.7 \pm 0.7 \mathrm{RPM}($ mean $\pm \mathrm{SE}, n=$ 10 rats/group) by 6 weeks after toxin administration in the saline treated animals. However, in the THL treated animals, the amphetamine-induced rotation was not increased with time, and the animal rotation, $1.1 \pm 0.2 \mathrm{RPM}$, was decreased $90 \%$ (Fig. 1B).

The apmorphine-induced rotation observed in this study, which administered the THLs at 1,2, and 3 weeks after the toxin (Fig. 1A), was expressed as a ratio of the RPM in the THL treated animals divided by the RPM in the saline treated rats at 3-6 weeks after toxin injection (Fig. 2). The same ratio was computed from the prior study (11), where the PD rats were treated with only a single injection of THLs at 

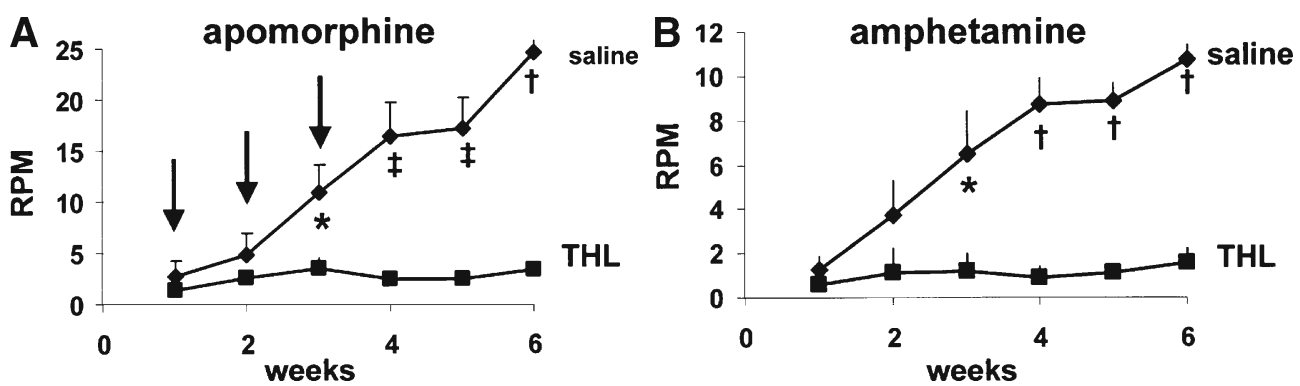

Fig. 1. Rotation measurements following the administration of either apomorphine (A) or amphetamine (B) for PD rats treated with either saline or THLs. Treatment was administered at 1, 2, and 3 weeks after toxin injection as indicated by the arrows in A. $R P M$ rotations per minute. Data are mean $\pm \mathrm{SE}$ ( $n=10$ rats/ group). Statistical differences from the saline treated animals are ${ }^{*} p<0.05,{ }^{\ddagger} p<0.005$, or ${ }^{\dagger} p<0.0005$ at 3,4 , 5 , or 6 weeks after toxin administration.

2 weeks after toxin administration, and these data are also plotted in Fig. 2. The comparison shows the marked improvement in neurological function with the repeat THL dosing.

An alternative measure of neurobehavior, the vibrissaeelicited forelimb placing test, was used to test the pharmacologic efficacy of the THL gene therapy. The unilateral 6-hydroxydopamine lesioned rat fails to place the forelimb contralateral to the lesion. The forelimb placement score was nearly perfect, $176 \pm 1$ (mean $\pm \mathrm{SE}, n=10$ rats/group), for the right forelimb, which is ipsilateral to the lesion, in either the saline treated or THL treated rats (Fig. 3). However, the forelimb placement score was reduced $77 \%$ on the left side in the saline treated animals to $41 \pm 4$ (Fig. 3). In contrast, the forelimb placement score was reduced only $18 \%$ in the THL treated rats, from $178 \pm 1$ to $146 \pm 7$ (Fig. 3 ).

The striatal TH enzyme activity was measured at 6 weeks after toxin administration for both the lesioned and nonlesioned sides of brain in the saline and THL treated rats, and these data are shown in Fig. 4. There was a 99\% reduction in striatal TH enzyme activity on the lesioned side in the saline treated animals (Fig. 4). However, the reduction in striatal TH enzyme activity was only $23 \%$ in the animals treated with THLs at 1, 2, and 3 weeks after toxin injection (Fig. 4). In contrast, the striatal $\mathrm{TH}$ was reduced $91 \%$ in the rats treated with a single injection of THLs at 2 weeks after toxin administration (Fig. 4).

\section{DISCUSSION}

The results of this study provide evidence for a near complete rescue of the toxic effects of intra-cerebral 6hydroxydopmine in experimental PD treated with GDNF gene therapy given intravenously and without viral vectors. The experimental design includes three different assays of neurobehavior (Figs. 1, 2, and 3), and measurements of striatal TH enzyme activity (Fig. 4). In comparison to the results of a previous study (11), the present investigation shows the greater therapeutic effect of GDNF gene therapy when THLs are given at repeat dosing early after toxin exposure.

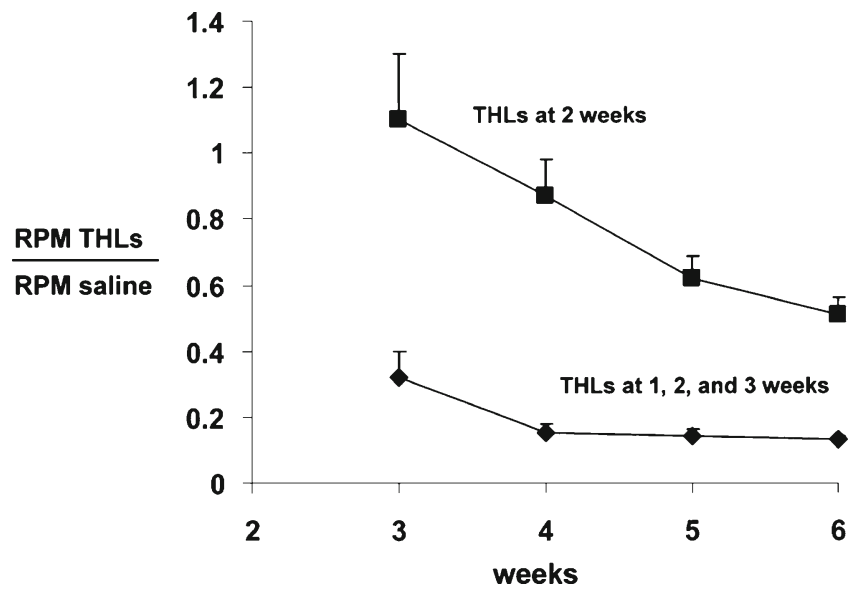

Fig. 2. The ratio of apomorphine-induced rotation in the THL treated rats divided by the apomorphine-induced rotation in the saline treated rats was derived from the data in Fig. 1 for the animals treated at 3-6 weeks, and from Xia et al. (11) for the rats treated with a single dose at 2 weeks after toxin administration. Data are mean \pm $\mathrm{SE}(n=10 \mathrm{rats} /$ group$)$.

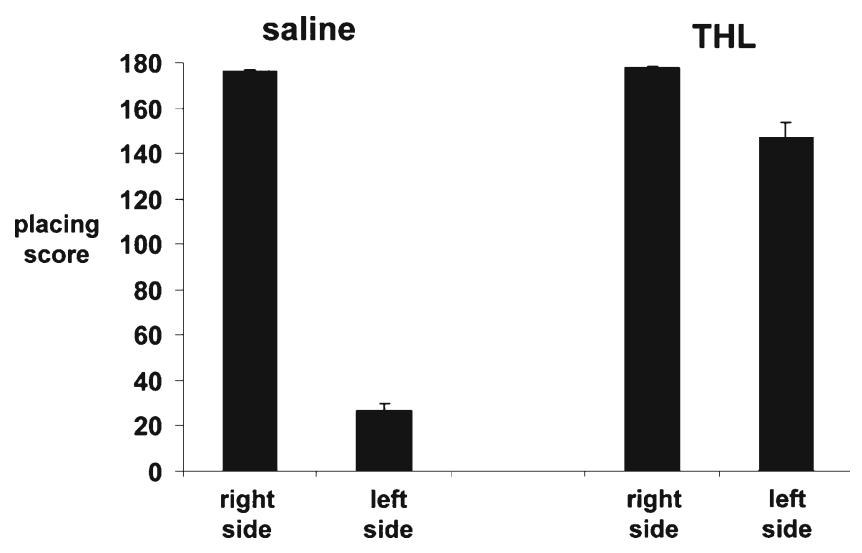

Fig. 3. Vibrissae-elicited forelimb placing test scores for right side, which is ipsilateral to the toxin lesion, and the left side, which is contralateral to the toxin lesion, for the saline treated rats and the THL treated rats. All scores were measured at 6 weeks following toxin injection, which is 3 weeks after the last THL administration. Data are mean \pm SE ( $n=10$ rats/group). 


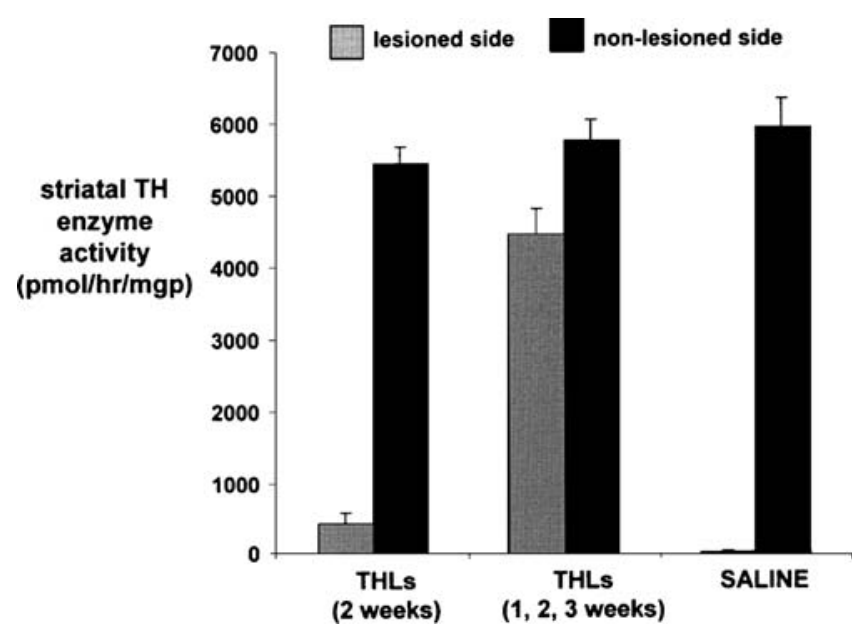

Fig. 4. Striatal TH enzyme activity on the lesioned side and the nonlesioned side in rats treated with either saline or THLs. THL treatment was administered at either 1,2 , and 3 weeks after toxin injection (this study) or as a single dose at 2 weeks after toxin injection (11). Striatal TH activity was measured at 6 weeks after toxin administration. Data are mean $\pm \mathrm{SE}$ ( $n=10$ rats/group).

In the present study, the control animals were treated with saline. Prior work showed there is no therapeutic effect in the experimental PD model when the rats are treated with a THL formulation that is identical to the TfRMAb-targeted THLs, except the TfRMAb is replaced by an $\mathrm{IgG} 2 \mathrm{a}$ isotype control antibody (19). Previous organ biodistribution studies show the brain targeting of the pegylated liposome is increased $>10$-fold following conjugation of the TfRMAb to the tips of the PEG strands on the surface of the THL (21). Previous histological studies demonstrated THL gene therapy, with a TH expressing plasmid DNA, causes an increase in TH enzyme activity throughout the striatum (19), and THL gene therapy, with a GDNF expressing plasmid DNA, causes an increase in GDNF in the substantia nigra (11). There are no side effects of repeat intravenous THL administration. A prior toxicity study showed no changes in serum chemistry or histology in brain or peripheral organs following the chronic weekly administration of THLs (22).

There are several aspects of the THL formulation, which enabled the successful therapeutic outcome. First, neurotrophin gene therapy, and in particular GDNF gene therapy, is known to rescue the nigra-striatal system in experimental PD when the GDNF gene is injected directly into the brain (6-10). The present study extends these findings to the experimental setting where the GDNF transgene is administered intravenously without viral vectors. This is enabled by encapsulating the GDNF plasmid DNA in $100 \mathrm{~nm}$ pegylated liposomes, which are targeted with a molecular Trojan horse - an MAb against the rat TfR. The TfR is highly expressed on the BBB (23), and enables the receptor-mediated transcytosis (RMT) across the BBB of either the endogenous ligand, transferrin, or a peptidomimetic TfRMAb (24). The incorporation of the TfRMAb in the THL formulation enables the plasmid DNA, encapsulated in the THL, to undergo RMT across the BBB (12-16). In addition, the TfR is highly expressed on neurons (25). Binding of the TfRMAb to the neuronal TfR enables the THL to undergo receptormediated endocytosis into neurons. This has been demonstrated previously for rodent and primate brain using a beta-galactosidase reporter plasmid DNA (12-16). Finally, the GDNF expression plasmid, pTHproGDNF, was engineered to place the preproGDNF transgene under the influence of the $8 \mathrm{~kb}$ of the 5'-FS of the rat TH gene (11). This restricts transgene expression in brain to the catecholaminergic system (26-29), which reduces potential off-target effects of the gene therapy.

The restricted nature of GDNF gene expression from the pTHproGDNF plasmid DNA was demonstrated in a previous study (11). Following the intravenous injection of THLs carrying the pTHproGDNF, GDNF expression was measured in a survey of peripheral rat tissues, and in multiple regions of the brain. The GDNF was expressed in brain only in the substantia nigra, and was only expressed in peripheral tissues, such as liver or adrenal gland, where the TH promoter is active. The highly restricted nature of GDNF gene expression under the influence of the $\mathrm{TH}$ promoter, as compared to the CMV promoter, was demonstrated previously in COS cells (11). The level of GDNF gene expression in COS cells was two to three log orders of magnitude reduced when the CMV promoter was replaced by the TH promoter (11).

The GDNF expression in the rat in vivo peaks at 6 days, and persists for at least 10 days, after a single THL administration (11). Therefore, in the present study, the THLs were administered weekly for three successive weeks, beginning at 1 week after toxin administration (Fig. 1A). With this treatment schedule, the nigral-striatal tract is believed to be exposed to sustained elevations in GDNF for approximately 4 weeks. This is corroborated by the observation of the much greater therapeutic effect with multiple THL dosing as opposed to single THL dosing (Fig. 2). The tissue concentration of GDNF is increased 2- to 8-fold in those organs that express the TH promoter (11). Thus, relatively modest increases in brain GDNF provide a marked degree of neuroprotection. This observation is consistent with studies producing an approximate 3 -fold increase in the local concentration of GDNF with a trans-cranial injection of a GDNF expressing viral vector (8). This modest increase in GDNF was highly neuroprotective in the nigral-striatal tract, but did not cause off-target effects or GDNF-induced neuronal sprouting (8).

In summary, the present study shows that a near complete recovery from a nigral neurotoxin is possible with intravenous, non-viral GDNF gene therapy given for 3 weeks early in the course of the evolution of the toxin-induced lesion. The plasmid DNA expressing the GDNF was delivered to all parts of the brain via the trans-vascular route across the BBB with Trojan horse liposomes. However, since the expression of the GDNF transgene was under the influence of the TH promoter, GDNF expression in the brain is confined to the narrow regions of brain that express the $\mathrm{TH}$ gene.

\section{ACKNOWLEDGEMENTS}

This work was supported by a grant from the Michael J. Fox Foundation for Parkinson's Research, and NIH grant NS-53540. 
Open Access This article is distributed under the terms of the Creative Commons Attribution Noncommercial License which permits any noncommercial use, distribution, and reproduction in any medium, provided the original author(s) and source are credited.

\section{REFERENCES}

1. L. F. Lin, D. H. Doherty, J. D. Lile, S. Bektesh, and F. Collins. GDNF: a glial cell line-derived neurotrophic factor for midbrain dopaminergic neurons. Science. 260:1130-1132 (1993). doi:10.1126/ science. 8493557.

2. B. J. Hoffer, A. Hoffman, K. Bowenkamp, et al. Glial cell linederived neurotrophic factor reverses toxin-induced injury to midbrain dopaminergic neurons in vivo. Neurosci. Lett. 182:107111 (1994). doi:10.1016/0304-3940(94)90218-6.

3. P. A. Lapchak, P. J. Miller, F. Collins, and S. Jiao. Glial cell linederived neurotrophic factor attenuates behavioural deficits and regulates nigrostriatal dopaminergic and peptidergic markers in 6-hydroxydopamine-lesioned adult rats: comparison of intraventricular and intranigral delivery. Neuroscience. 78:61-72 (1997). doi:10.1016/S0306-4522(97)83045-X.

4. A. J. Kastin, V. Akerstrom, and W. Pan. Glial cell line-derived neurotrophic factor does not enter normal mouse brain. Neurosci. Lett. 340:239-241 (2003). doi:10.1016/S0304-3940(03)00007-7.

5. N. K. Patel, M. Bunnage, P. Plaha, et al. Intraputamenal infusion of glial cell line-derived neurotrophic factor in PD: a two-year outcome study. Ann. Neurol. 57:298-302 (2005). doi:10.1002/ana.20374.

6. J. H. Kordower, M. E. Emborg, J. Bloch, et al. Neurodegeneration prevented by lentiviral vector delivery of GDNF in primate models of Parkinson's disease. Science. 290:767-773 (2000). doi:10.1126/science.290.5492.767.

7. B. Georgievska, D. Kirik, and A. Bjorklund. Aberrant sprouting and downregulation of tyrosine hydroxylase in lesioned nigrostriatal dopamine neurons induced by long-lasting overexpression of glial cell line derived neurotrophic factor in the striatum by lentiviral gene transfer. Exp. Neurol. 177:461-474 (2002). doi:10.1006/exnr.2002.8006.

8. A. Eslamboli, B. Georgievska, R. M. Ridley, et al. Continuous low-level glial cell line-derived neurotrophic factor delivery using recombinant adeno-associated viral vectors provides neuroprotection and induces behavioral recovery in a primate model of Parkinson's disease. J. Neurosci. 25:769-777 (2005). doi:10.1523/ JNEUROSCI.4421-04.2005.

9. M. Brizard, C. Carcenac, A. P. Bemelmans, et al. Functional reinnervation from remaining DA terminals induced by GDNF lentivirus in a rat model of early Parkinson's disease. Neurobiol. Dis. 21:90-101 (2006). doi:10.1016/j.nbd.2005.06.015.

10. N. A. Do Thi, P. Saillour, L. Ferrero, T. Paunio, and J. Mallet. Does neuronal expression of GDNF effectively protect dopaminergic neurons in a rat model of Parkinson's disease? Gene Ther. 14:441-450 (2007). doi:10.1038/sj.gt.3302844.

11. C. F. Xia, R. J. Boado, Y. Zhang, C. Chu, and W. M. Pardridge. Intravenous glial-derived neurotrophic factor gene therapy of experimental Parkinson's disease with Trojan horse liposomes and a tyrosine hydroxylase promoter. J. Gene. Med. 10:306-315 (2008). doi:10.1002/jgm.1152.

12. W. M. Pardridge. Gene targeting in vivo with pegylated immunoliposomes. Methods Enzymol. 373:507-528 (2003). doi:10.1016/S0076-6879(03)73032-8.

13. N. Shi, Y. Zhang, R. J. Boado, C. Zhu, and W. M. Pardridge. Brain-specific expression of an exogenous gene after i.v. administration. Proc. Natl. Acad. Sci. USA. 98:12754-12759 (2001). doi:10.1073/pnas.221450098.
14. Y. Zhang, F. Schlachetzki, and W. M. Pardridge. Global non-viral gene transfer to the primate brain following intravenous administration. Mol. Ther. 7:11-18 (2003). doi:10.1016/S1525-0016(02) 00018-7.

15. Y. Zhang, F. Schlachetzki, J. Y. Li, R. J. Boado, and W. M. Pardridge. Organ-specific gene expression in the rhesus monkey eye following intravenous non-viral gene transfer. Mol. Vis. 9:465-472 (2003).

16. C. Zhu, Y. Zhang, Y. F. Zhang, et al. Organ-specific expression of the lacZ gene controlled by the opsin promoter after intravenous gene administration in adult mice. J. Gene. Med. 6:906-912 (2004). doi:10.1002/jgm.575.

17. C. F. Xia, C. Chu, J. Y. Li, et al. Comparison of cDNA and genomic forms of tyrosine hydroxylase gene therapy of the brain with Trojan horse liposomes. J. Gene. Med. 9:605-612 (2007) doi:10.1002/jgm.1046.

18. W. M. Pardridge. Non-viral gene transfer across the blood-brain barrier with Trojan horse liposomes. In T. Friedmann, and J. Rossi (eds.), Gene Transfer: Delivery and Expression of DNA and RNA, Cold Spring Harbor Laboratory Press, Cold Spring Harbor, 2007, pp. 701-710.

19. Y. Zhang, F. Calon, C. Zhu, R. J. Boado, and W. M. Pardridge. Intravenous nonviral gene therapy causes normalization of striatal tyrosine hydroxylase and reversal of motor impairment in experimental parkinsonism. Hum. Gene. Ther. 14:1-12 (2003). doi:10.1089/10430340360464660.

20. K. K. Anstrom, T. Schallert, M. T. Woodlee, A. Shattuck, and D. C. Roberts. Repetitive vibrissae-elicited forelimb placing before and immediately after unilateral 6-hydroxydopmaine improves outcome in a model of Parkinson's disease. Behav. Brain Res. 179:183-191 (2007). doi:10.1016/j.bbr. 2007.01.028.

21. N. Shi, and W. M. Pardridge. Non-invasive gene targeting to the brain. Proc. Natl. Acad. Sci. USA. 97:7567-7572 (2000). doi:10.1073/pnas.130187497.

22. Y. F. Zhang, R. J. Boado, and W. M. Pardridge. Absence of toxicity of chronic weekly intravenous gene therapy with pegylated immunoliposomes. Pharm. Res. 20:1779-1785 (2003). doi:10.1023/B:PHAM.0000003375.13655.f9.

23. J. Huwyler, and W. M. Pardridge. Examination of blood-brain barrier transferrin receptor by confocal fluorescent microscopy of unfixed isolated rat brain capillaries. J. Neurochem. 70:883886 (1998)

24. S. Skarlatos, T. Yoshikawa, and W. M. Pardridge. Transport of $\left.{ }^{125} \mathrm{I}\right]$ transferrin through the rat blood-brain barrier in vivo. Brain Res. 683:164-171 (1995). doi:10.1016/0006-8993 (95)00363-U.

25. T. Moos, P. S. Oates, and E. H. Morgan. Iron-dependent neuronal expression of transferring receptor mRNA in the rat Mol. Brain Res. 72:231-234 (1999). doi:10.1016/S0169-328X(99) 00226-0.

26. N. Kaneda, T. Sasaoka, K. Kobayashi, et al. Tissue-specific and high-level expression of the human tyrosine hydroxylase gene in transgenic mice. Neuron. 6:583-594 (1991). doi:10.1016/08966273(91)90061-4.

27. M. A. Kessler, M. Yang, K. L. Gollomp, H. Jin, and L. Iacovitti. The human tyrosine hydroxylase gene promoter Brain Res. Mol. Brain Res. 112:8-23 (2003). doi:10.1016/ S0169-328X(02)00694-0.

28. N. Min, T. H. Joh, K. S. Kim, C. Peng, and J. H. Son. $5^{\prime}$ upstream DNA sequence of the rat tyrosine hydroxylase gene directs high-level and tissue-specific expression to catecholaminergic neurons in the central nervous system of transgenic mice. Mol. Brain Res. 27:281-289 (1994). doi:10.1016/0169-328X(94) 90011-6.

29. T. E. Kim, M. J. Park, E. J. Choi, et al. Cloning and cell typespecific regulation of the human tyrosine hydroxylase gene promoter. Biochem. Biophys. Res. Commun. 312:1123-1131 (2003). doi:10.1016/j.bbrc.2003.11.029. 